\title{
PUBLISHING
}

\section{Pacific Journalism Review Twenty years on the front line of regional identity and freedom}

\begin{abstract}
Pacific Journalism Review has consistently, at a good standard, honoured its 1994 founding goal: to be a credible peer-reviewed journal in the Asia-Pacific region, probing developments in journalism and media, and supporting journalism education. Global, it considers new media and social movements; 'regional', it promotes vernacular media, human freedoms and sustainable development. Asking how it developed, the method for this article was to research the archive, noting authors, subject matter, themes. The article concludes that one answer is the journal's collegiate approach; hundreds of academics, journalists and others, have been invited to contribute. Second has been the dedication of its one principal editor, Professor David Robie, always, somehow providing resources - at Port Moresby, Suva, and now Auckland-with a consistent editorial stance. Eclectic, not partisan, it has nevertheless been vigilant over rights, such as. monitoring the Fiji coups d'etat. Watching through a media lens, it follows a 'Pacific way', handling hard information through understanding and consensus. It has 237 subscriptions indexed to seven databases. Open source, it receives more than 1000 site visits weekly. With 'clientele' mostly in Australia, New Zealand and 'Oceania', it extends much further afield. From 1994 to 2014, 701 articles and reviews were published, now more than 24 scholarly articles each year.
\end{abstract}

Keywords: academic publishing, environment, journalism education, political journalism, Fiji, human rights, media freedom, New Zealand, Pacific way, Papua New Guinea, sustainable development, vernacular media

\section{LEE DUFFIELD}

Queensland University of Technology

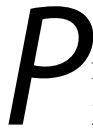

ACIFIC JOURNALISM REVIEW since its inception has always emphasised its regional identity, adopting its own 'Pacific' style of discourse and inquiry. For 20 years it has been focused on Pacific issues, for and by people and institutions of the region-while always open to linkages and inputs from major global centres. It commenced publication at the University of Papua New Guinea in 1994, was later published from the University of the South Pacific in Fiji in 1998, and then from the

18 PACIFIC JOURNALISM REVIEW 21(1) 2015 
Auckland University of Technology, since 2002. For its inspiration, the first editorial, by founder David Robie noted an expansion of media services in the South Pacific region, but 'surprisingly little reflective journalism or analysis of the state of the media today in the Pacific, or of issues such as freedom of information, freedom of expression, ethics, ownership, gender in media, development, and the public relations industry ...' (PJR, 1(1), 1994).

The journal promised redress, and the key elements of the 32 editions up to the end of 2014, studied for this review, show how the effort was made to bring on a change. It would sponsor free circulation of information and protection of media rights, while also supporting reflective analysis of media, media probity and accountability. Pacific Journalism Review took up three roles in its South Pacific context: (1) It is an academic journal; (2) it is a professional forum for journalists about journalism, and (3) it is concerned with journalism education. As it states, it is the only specialist media, journalism and political studies research journal based in New Zealand; and the only one globally that specialises in the Asia-Pacific with emphasis on the Pacific (PJR Notes, 2014).

\section{Political problems in the Pacific}

Creating an outlet for thought and change in this distinctive part of the world would be an inviting task, but things would go wrong with circumstances on the ground. Dysfunctional politics in the region have meant that for most of its existence Pacific Journalism Review has found itself taking a lead, dealing with an ongoing challenge to journalism and scholarship. Alan Robson from the University of the South Pacific in Fiji described the situation in the second edition of the PJR:

Events in recent years in the South Pacific have dispelled hitherto widely held perceptions of the region as a peacefully modernising backwater of traditional societies. In particular the 1987 coups in Fiji galvanised the attention of politicians and academics. But in truth, this was just one of a series of crises besetting the South Pacific island states ... a range of events (dealt with) under the rubric of responses to colonialism and the emergence of Pacific nationalism. (PJR, 2(1), 1995)

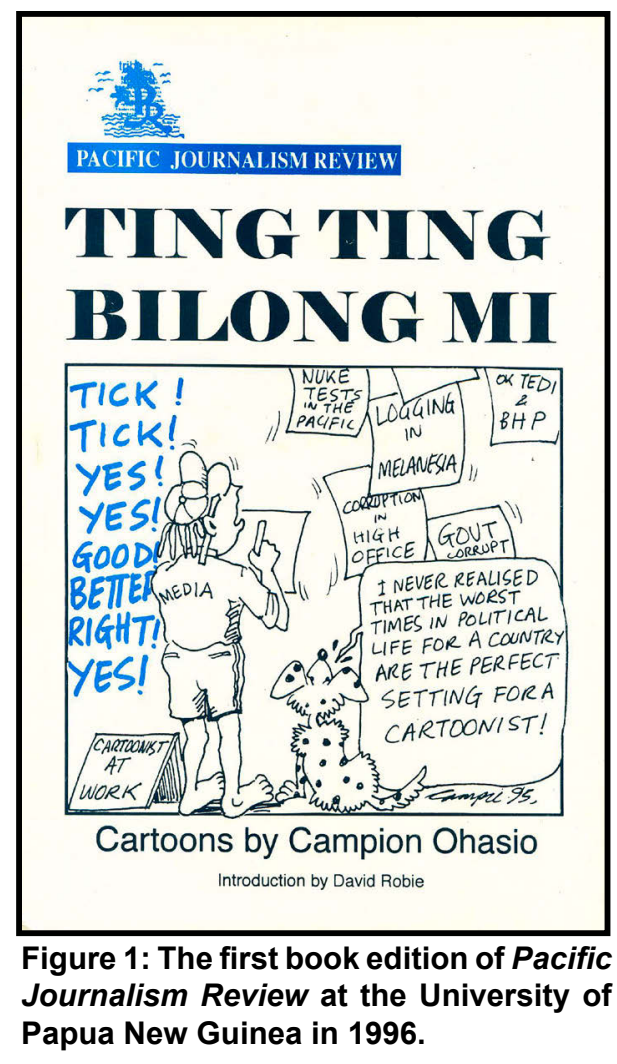

PACIFIC JOURNALISM REVIEW 21 (1) 2015 
POLITICAL JOURNALISM IN THE ASIA-PACIFIC

Similarly Martin Hadlow, from the University of Queensland (later Secretary-General of the AMIC research centre in Singapore) identified dilemmas for media, writing after the UNESCO World Press Freedom Day celebrations in Brisbane (an occasion like many others seized on by the $P J R$ as a ready source for quality material):

Geographical remoteness, small populations and vast sea distances between nations are all factors which go to ensuring that the islands of the Pacific remain relatively unfamiliar territory to many in the international community. That a region so wealthy in languages, cultures and social traditions could also be a place of coups and tensions and where media freedoms are often trampled upon, is also little known to many casual observers. (PJR, 16(2), 2010)

He said there was a need for 'independent Pacific media voices to be heard and for press freedom activists to express concerns on the international stage'. The interests of 'outside powers', in the post-colonial era would also go into the mix of problems: demands of foreign corporations, the usually benign if pervasive influence of Australia, New Zealand and the European Union; continuing French involvement in government of territories; the geo-political jostling of the United States, Taiwan, and the 'new' participant China, rapidly extending its economic and 'soft power' interests.

\section{Following a 'Pacific Way'}

Many absorbing issues for media and journalists have been explored through the PJR despite having to attend to conflicts and break-down in the countries of the region; issues like journalism for development, conservation of the environment, preserving custom, and the question of evolving indigenous ways of problem solving and communication. After the first nine years of publication, with the PJR moving to Auckland, it could claim to have been 'at the forefront of critical reflections on the role of the media and journalism practices in the Pacific region' (King, 9(1), 2003).

It has continued appealing to its imagined and actual community, with a large overlap among contributors and readers, being people in the region from the mass media, business, government and semi-government agencies, and political leaders. Often enough it was a direct and personal appeal, under the proactive, not to say entrepreneurial editorship of Robie, who would continue in the role for the full 20 years, and beyond. Distinguished people within and outside of the academic field would be invited to contribute, with some stimulating results, as with an article from the sometimes embattled Chief Ombudsman of Papua New Guinea, or the publication of a key speech by a New Zealand Prime Minister. The journal also collaborates closely with partner institutions; especially with USP, the Asian Media Information and Communication Centre (AMIC) in Singapore, and the Australian Centre for Independent Journalism, University of Technology of Sydney, Sydney. (PJR Notes, 2014).

20 PACIFIC JOURNALISM REVIEW 21(1) 2015 
More than just a matter of ingenuity, the gathering together of resources and talent, had its cultural dimension. It was a recognition that in this region, everybody might be involved. It means openness with little formality. Different perspectives are brought in and tolerated. It might draw on custom; on surviving aspects of colonial cultures, e.g. promoting education for development, or the plain fact of the region being a small world. It might be called a Pacific way. Something like this was invoked by Sandra Kailahi, of TV New Zealand and the Pacific Islands Media Association, from the viewpoint of Pasifika people, which she called 'Pacificness' - 'telling our side of the story':

Pasifika people face increased marginalisation if they do not become active participants in any media discourse. Newer, portable technologies open opportunities for smaller societies to become part of the media landscape. There are now more opportunities for smaller voices to express their Pacificness and be heard over the din of the mainstream. (PJR, 15(1), 2009).

An important challenge for South Pacific media, said Robie, was to be 'developing forms of journalism that contribute to the national ethos by mobilising change from passive communities to those seeking change ...' (PJR, 19(1), 2013). To that end, the $P J R$ would be collaborative, mobilising the talents of a spread of writers, as in his 1995 book Nius Bilong Pasifik:

The idea was to provide materials to help teaching and for students to reference and also for the media industry to use. The contributors were both academics and Pacific industry journalists. I was an admirer of the Australian Journalism Review under John Henningham, and also Index on Censorship, and drew ideas from both publications. (Robie, D., Personal communication, 11 November 2014; see also www.amazon.com/Nius-Bilong-Pasifik-Media-Pacific/dp/9980840528).

\section{Academic standards}

Over time the Pacific Journalism Review can be seen shifting towards more recognition and renown as an academic journal; while maintaining its eclectic policy on subjects and writers, and persisting often less formally, with its pictures, commentaries and cartoons, as a forum for Pacific media. That shift, a process of over a decade, has been marked by more regular and consistent publication, resulting in the unfailing production of biannual editions. The change has been on the back of a stronger support base at the larger university, in Auckland. Success in this field has been marked by the journal's acceptance by international research databases.

While developing, PJR has nevertheless always met the standard of a substantial academic publication. What ensured the quality of the journal, in particular, was its reviewing policy; every article double-blind peer reviewed. It took great trouble for a small operation to guarantee this, by enrolling a pool of associates to review articles. That 
POLITICAL JOURNALISM IN THE ASIA-PACIFIC

was part of the resourcefulness of the journal, always looking out for and assembling resources. Even in its commentaries on issues, where guest writers or VIP contributors are invited, the PJR policy is to apply uniform quality assurance. All commentaries are normally refereed the same as research articles, except for certain ones such as keynote speeches, which will still be edited and referenced (Robie, D., Personal communication, 11 November 2014).

In 2010, PJR was graded at level B by the Australian Research Council, a category that included leading regional journals and those accommodating early career researchers. The Australian Journalism Professors Council recommended to the ARC that it be rated level A (Knight, 2011; Robie, 2011), and a case made to the ARC averred that 'almost all papers are by well-established researchers with reputations ... While the leading global source in a strategic field, South Pacific media and civilisation, PJR engages with the international research community also as a main outlet for general writing about media. This attracts submissions and restricts acceptances' (Duffield, 2011). In the event, the ARC journal ratings system was abandoned before cases for regrading were heard.

\section{Defending journalism}

The academic Discipline of Journalism being a professional discipline, the question of quality is not only one of academic probity, but of how this journal would support journalists, especially in a time of trouble. It is the defence of journalism, journalists and journalistic standards. This raises the matter of how things 'went wrong' politically for the peaceable project of Pacific Journalism Review. It has had to devote much of its resources - much space, time and energy - to monitoring conflict and large scale crime, not least military forces seizing political power. Under whatever government regime, attacks on the news media have been part of a dysfunctional political and economic environment across the region. The media community has had a strongly felt obligation to step up, to contest the issue. A special report on the history of such troubles, and on the state of media freedom, by Alex Perrottet and David Robie would conclude:

Pacific media freedom has been under siege for more than a decade, particularly since an attempted coup in Fiji in May 2000, when a television station was attacked and ransacked, a foreign journalist was shot and wounded and a local journalist ended up being imprisoned for treason. Since then various Pacific countries, notably Fiji, Papua New Guinea, Tonga and Vanuatu, have faced various periods of media repression. Since the military coup in December 2006, Fiji has faced arguably its worst sustained pressure on the media since the original two Rabuka coups of 1987. (PJR, 17(2), 2011)

A survey by Som Prakash and Shailendra Singh, had drawn the same conclusions, identifying 'landmark changes' in three island states:

22 PACIFIC JOURNALISM REVIEW 21(1) 2015 
Fiji, beset by racial and political problems culminating in three coups ... Tonga, a Polynesian monarchy, has recently seen an unprecedented number of protest marches against the ruling elite ... In the Solomons, a strong desire for a fairer political system was manifested in the 2006 riots in Honiara... The media has been a key player in these events. Regularly accused of adding fuel to fire in its coverage of crises, the media faces constant government pressure in all three countries ... (PJR, 12(2), 2006).

\section{Anatomy of Pacific Journalism Review}

What is this product that has sustained innovation and respect for 'vernacular' cultures, ensured academic best practice in assessing contributions, and supported journalists standing up to the imprecations of an insecure dictatorship? For this research into the $P J R$, the writer reviewed every edition to date; (1) seeking to anatomise the journal by its structure and a categorisation of contents; (2) finding material that broadens these observations, e.g. on management and resourcing of the operation, and (3) drawing inferences as to the meanings of contents of the articles, in the context of the journal's history and stated mission.

\section{Structure and contents}

Key elements of Pacific Journalism Review have already been mentioned, as an academic journal, a professional forum for journalists about journalism, and a publication concerned with journalism education. This developed over time, so that by the present decade it had taken up a standard template, though not with predictable contents, providing an editorial article at the start; a themed section occupying usually half the edition; some articles on other topics set together; most likely a special report or feature, such as the photo essay in November 2014 (20(2), 2014); and an extensive set of book reviews. The sections are:

Media profiles._An early series of media profiles where interviewers, mostly Journalism students, would recount the work of leading practitioners, (in 1994, Sophie Kuasi and Nino Kami, on work by Wendy Bacon, Neville Togarewa and Abby Yadi).

Aforum section for guest writers, starting in the first edition (1(1), November 1994) 
POLITICAL JOURNALISM IN THE ASIA-PACIFIC

with the University of Papua New Guinea library studies academic Margaret Obi's welcome to PJR: 'This first issue of PJR offers a smorgasbord of journalistic skills from James Pinder to Jessie Waibauru — from the experienced to the potential...' She acclaimed the promised focus on professional ethics, journalistic responsibility and accountability, and publishing 'without fear or favour'.

Support for investigative journalism, defining it and providing defence of the journalists concerned if in trouble (a policy initiated with special coverage of the 1996 Pacific Investigative Journalism awards, in Vol 3(2), that year). As early as 2005 a section called 'Frontline' first appeared, publishing investigative reports, with two articles on Aboriginal land rights in Australia. 'Frontline' is now a regular feature, e.g. with reports in Vol 18(1), 2012, based on investigations into West Papua's Freeport mine at Grasberg and the Vale nickel refinery at Goro in New Caledonia. In one of the journal's reviewing or republishing exercises, to expose quality material, editor Marni Cordell of New Matilda in Vol 15(2), 2009, on investigative work by ABC Four Corners, provided a definition: 'The purpose of investigative journalism is to hold powerful interests to account and highlight systemic corruption and breakdown ... to bring attention to injury and injustice, expose information that is in the public interest, and encourage legislative reform.' The work on investigative journalism was associated with the arguments for journalism as a form of research, led by Wendy Bacon from UTS, and Chris Nash from Monash University, a concept publicised in PJR and achieving recognition from the ARC (Bacon, 2012). It is a substantial polemic bringing together academic and journalistic conceptions of thought where this journal is playing an important facilitating role.

Pacific Journalism Review has always stood out in academic publishing with its extensive use of illustration, seen as part of the information flow and truth telling. This has included three photo essays by the photojournalist Ben Bohane, and many cartoonists from the region, or nearby, (the first, Campion Ohasio, featured in Vol 3(2), 1996, with his series 'Ting Ting Bilong Mi', commenting during the Bougainville and Sandline mercenary crisis: 'I never realised that the worst times in political life for a country are the perfect setting for a cartoonist'). Increasingly investigation has taken the form of video documentaries, often enough connected with PJR's institutional base, the Pacific Media Centre, accompanied by articles and reviews in the journal and online, (e.g. Jim Marbrook's Cap Bocage on New Caledonia mining; Max Stahl, documentary making on Timor-Leste; see also Sasya Wreksono's 2014 student video on PJR itself).

Themed editions were published from the earliest years, initially as articles accepted and grouped, in the last seven years becoming more systematic, with advertising for contributions, and commissioning, so that on average ten articles will appear in the themed section, half the edition's total including editorials and reviews. An average 2.75 general articles, on other subjects, will appear in each edition. The themes include: East Timor and West Papua; Coverage of Crises, and the Uni Tavur testimony (eyewitness

24 PACIFIC JOURNALISM REVIEW 21(1) 2015 
treatments of the deaths of four students in a protest against World Bank interventions, at Port Moresby, 2001).

Commentaries have been Fiji Media Bill (Richard Naidu); Synthesising Industry and Academic Ambitions (Kerry Green), and Politics of Media (Steven Ratuva), in 9(1), 2003; the Indigenous Public Sphere, six articles, 11(1), 2005; HIV Aids Campaigns in PNG (Trevor Cullen), 12(1), 2006; the Changing Mediascape in New Caledonia, (Nick Maclellan), 15(2), 2009; Journalism training in New Zealand-for the 'real world'? (Lyn Barnes), 19(1), 2013.

Editorials. Each of the 32 editions has led with an editorial; the first nine and most of the others by Robie as the editor-in-chief. However, from the ninth edition onward, 18 of the 23 numbers have been jointly edited with other contributors, and in four cases entirely by guests. The concerns of the editorials closely follow the themes in each edition. The practice of $P J R$ in drawing on intellectual and professional or industry events - conventions, conferences, forums - sees convenors or editors from a recent event working on the edition.

This publishing from intellectual congresses, together with the recruitment of individual academics or journalists as associates of the journal or the PMC, provides quality material, augments the editorial workforce and injects diversity of approach. That is especially so in the case of the affiliation with UTS over virtually the whole 20 -year period. As an example of co-editing, and drawing from a body of prepared papers, Vol 16(2), 2010, was co-edited with Robie by Marsali Mackinnon and Martin Hadlow from the UN Press Freedom Day conference at Brisbane. Editions by guests have been: Wayne Hope, Media Ownership and Democracy, 10(2), 2004; Barry King and Ian Goodwin, Media and the Indigenous Public Sphere, 11(1), 2005; Allison Oosterman and Janet Bedggood, Contemporary Gender Issues, 12(1), 2006; Wendy Bacon, Investigative Journalism Trends, 20(1), 2014. Co-editors of other editions: Wendy Bacon (five additional issues), Jean-Claude Bertrand, Catriona Bonfiglioli, Patrick Craddock, Lee Duffield, Rosser Johnson, Johan Lidberg, Fran Molloy, Tom Morton, Chris Nash (four editions), Ian Richards, Alan Samson, Shailendra Singh (two editions) and Charu Upal.

Reviews. Pacific Journalism Review has consistently reviewed scholarly and journalistic books, mostly published in the region or focused on regional issues to do with freedom or media. The reviews have also provided a way for the journal to open its coverage to much wider issues; for example, the treatment of Philip Knightley's The Latest Casualty, on 'media failure' in handling international crises, (Louise Matthews, 9(1), 2003); and Robert Fisk's polemical Great War for Civilisation (Jon Stephenson, 12(2), 2006). There have been 202 full analytical reviews, running to 1500 words, and 15 shorter notes on books.

Table 1 (following pages) summarises the output of Pacific Journalism Review, in the classifications explained above, in its first 20 years. 
POLITICAL JOURNALISM IN THE ASIA-PACIFIC

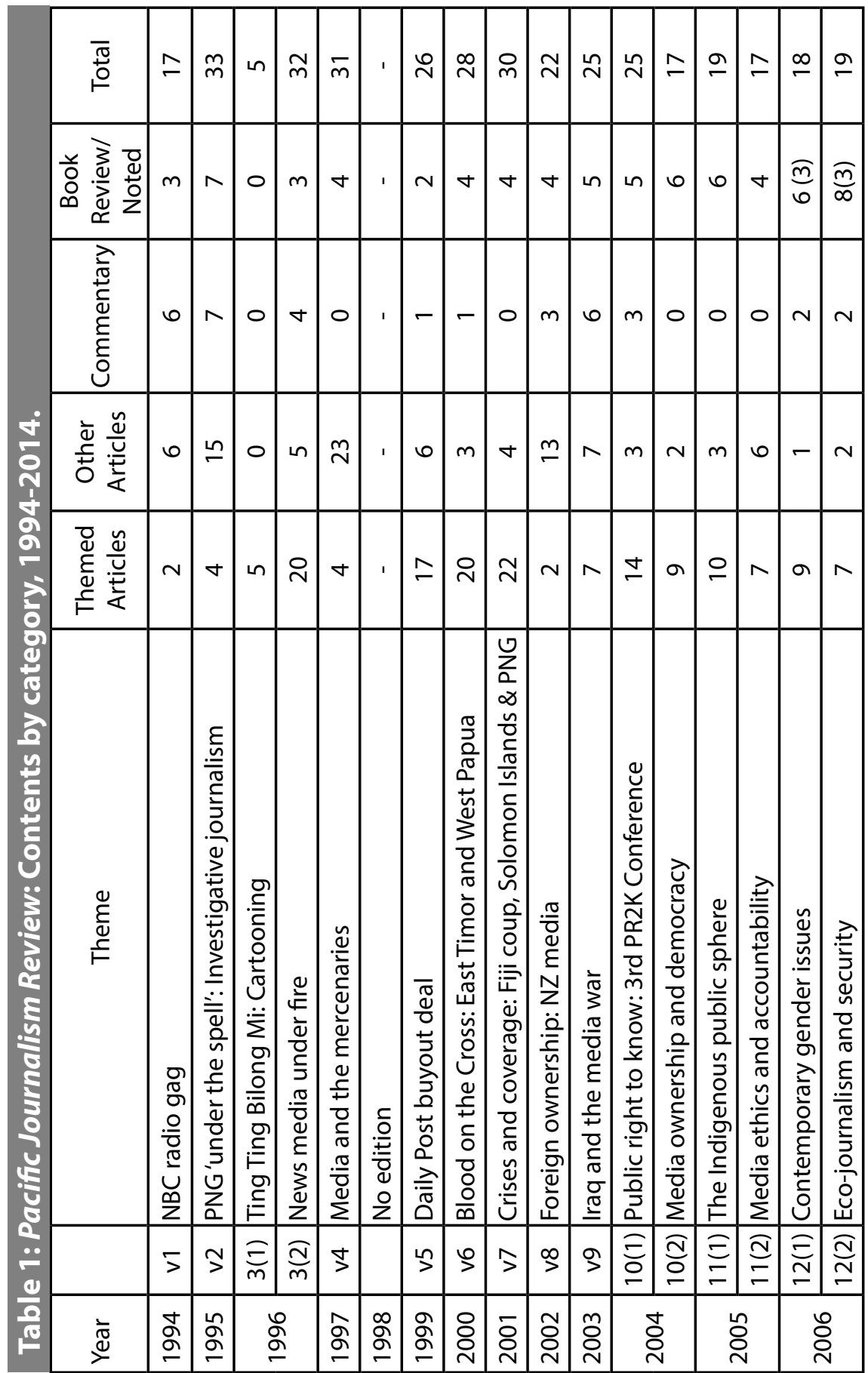

26 PACIFIC JOURNALISM REVIEW 21(1) 2015 
POLITICAL JOURNALISM IN THE ASIA-PACIFIC

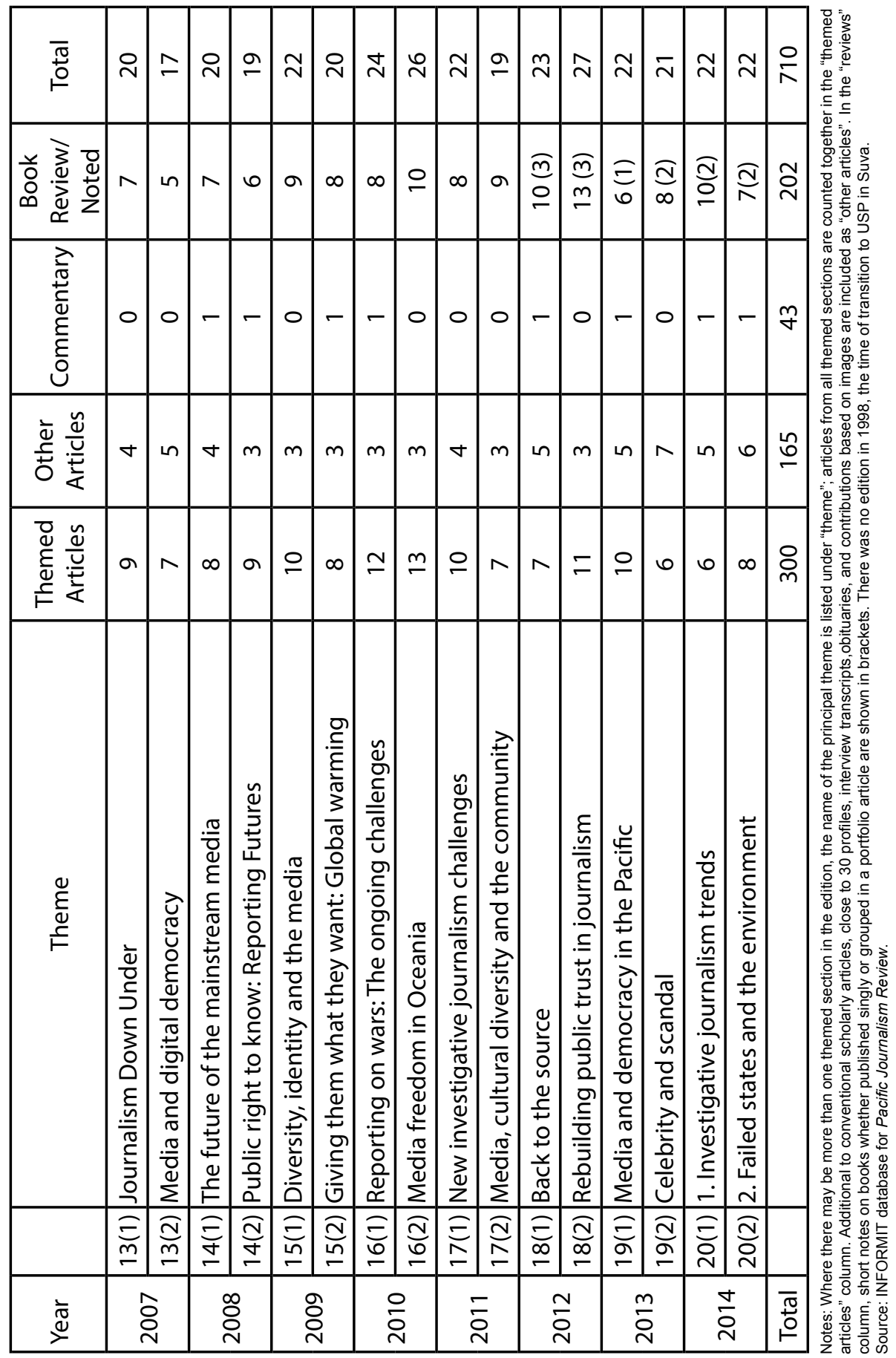


POLITICAL JOURNALISM IN THE ASIA-PACIFIC

\section{Management and resources of the publication}

It can be seen from the above that Pacific Journalism Review has operated on a very rich base, except for funding, where it has nevertheless achieved stability on the platform provided by AUT since the move there in 2002. As a print publication, it had 237 subscriptions in 2013, mostly with libraries and media organisations, in several countries of the region, plus Europe and North America. Of the subscriptions, 101 were in New Zealand, with 36 members of the Journalism Education Association of New Zealand (JEANZ) receiving copies. With service to NZ journalism included in the mission of the journal, there is reciprocity; both leading journalists from that country, viz Michael Field, and several media academics, viz Philip Cass, publish in it, assist with editing, provide a main-stay. (See PMC Annual Report, 2014).

Given the drive to provide an eclectic mix of materials - whether predominantly academic, predominantly journalistic or pedagogical in approach - the management task has been to find the means to publish a big edition each time. PJR numbers, bar one, have always had at least 16 articles; the largest by article numbers, at 33, was the second edition, in 1995 - although only 163 pages. Until 2002 editions were usually up to 200 pages, more since then; the 2014 numbers have 262 and 267 pages respectively. They have established a standard of close to one-third of contents being Māori or Pacific research articles.

With the drive to publish more in digital formats, especially since $2000, P J R$ was accepted in 2011 by the highly competitive SCOPUS database, one of the two main research metrics databases. It was already being indexed with full text articles by five international databases, EBSCO and Gale Cengage (USA), Informit (Australia), Newxtext (NZ) and PINI (Pacific Islands News and Information). Statistics from its own site (www.pjreview. info, 15 November 2014), also carrying a full-text archive, indicate significant interest. For example, the weekly report average for May-June 2013 was 1676 page visits (of which 555 unique users, 466 first-time). The top country users were NZ (28.09 percent), Australia (19.41 percent), USA (9.03 percent), Fiji (7.23 percent), UK (6.76 percent), Sweden, Canada, India and France (together 10.31 percent), and PNG (1.46 percent). Where institutions like university libraries subscribe to $P J R$ an accompanying online version has become de rigeur and a boon for researchers.

The online service from the Pacific Media Centre (www.pmc.aut.ac.nz - 15 November 2014) in May-June 2013 had 2082 page visits (1282 unique users, 1074 first-time), (PJR Media Release, 28 August 2012). It aggregates a plethora of news from the Centre, offerings from its off-shoot publications including PJR and Pacific Journalism Monographs, social media links, and a showcase for new video products. Also in this suite, Pacific Media Watch monitors media stories of note for the Pacific, threats to media and accountability issues for the journalists; Pacific Scoop is its own outlet for news reports or special investigations. In 2012, Pacific Media Watch had published 9092 articles, audio reports and videos; PMC Online news and database had hosted 2486 average weekly

28 PACIFIC JOURNALISM REVIEW 21(1) 2015 
unique visitors and file downloads; and there had been 99890 video views on the PMC's YouTube channel - exceeding 100,000 by early February 2015 (PMC Annual Report, 2014). As a part of AUT, the Centre, established in 2007, has access to student products and makes real the intention expressed in the first edition of PJR: to provide an outlet for the coming generations of journalists, and to enjoy their energy and initiative.

Digital publishing has been discussed in successive editions as a prime option for establishing an indigenous media, and community-based media for islands, e.g. in such contexts as the themed edition on the Indigenous Public Sphere, Vol 11(1), 2005, (canvassing developments in Māori media, Kalafi Moala's 'Case for Pacific Media Reform', and Michael Meadows's work on Australian indigenous radio and television). See also Kylie Anderson's 'Whither Pacific "traditional media"?: Internet technology in political education and participation', Vol 13(2), 2007-surveying internet developments in 12 Pacific countries.

As has been pointed out, $P J R$ is not well-funded, doing without large ongoing grants or endowments, while it canvasses good collegiate and 'in kind' support. That includes the strategic partnering of this Pacific-orientated journal with other institutions, and linking of its publication schedules to events that would produce copy for themed editions. This activity is both synergising, and cost saving, as with, for a further example, the joint edition produced with the CIJ in Sydney, following on from the latter's Public Right to Know conference in 2008, (PJR, 14(2), September 2008). On occasion grant funding has been obtained, like: funding from the Communication Assistance Foundation, the Netherlands, for Vol 3(2), 1996; funding from UNESCO, jointly with the Pacific Writing Forum at USP, Suva, for Vol 5(1), 1999; and a grant

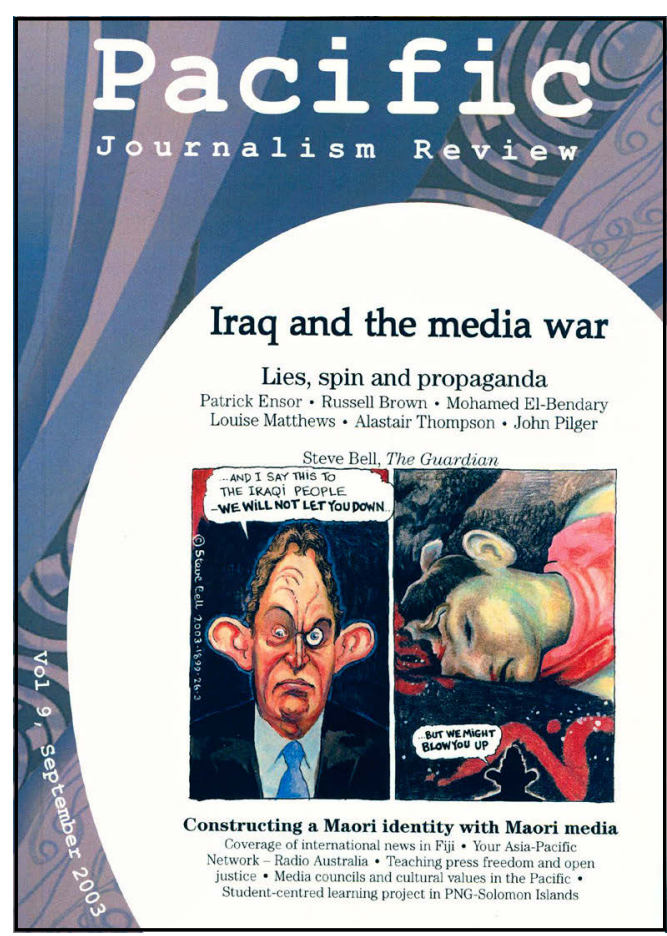

Figure 3: The first edition of $P J R$ published by AUT University in 2003. from the UNESCO Office of Pacific States for Vol 16(2), 2010, the edition following the UNESCO World Press Freedom Day event at Brisbane. External funding reached \$60,000 during 2010-13 (Pearson, 2013)

\section{Meanings, mission and editorial policies}

As a reflection of quality, the wide range of contributors, and the presence of distinguished 
POLITICAL JOURNALISM IN THE ASIA-PACIFIC

contributors helps to confer status on the publication. Addressing the 2011 ERA journal review, it listed three Prime Ministers who had contributed; Samoan chief Savea Sano Malifa, winner of the Commonwealth Astor Award for Media Freedom; the American theorist Robert W McChesney; the PNG Chief Ombudsman Chronox Manek, and the United States investigative journalist Bethany McLean.

External assessor Mark Pearson, a contributor as well in his field of ethics and media law, in 2013 credited the PMC, incorporating the academic journal, with high achievement and quality: 'While only a small team, its research outcomes have considerable impact and influence on policy making at an international level. It attracts international students and senior researchers and is internationally acclaimed as a research entity ...' Pearson's official audit also draws attention to the editorship of David Robie, urging the host university to allocate more funding, and to provide for eventual succession, and continuity. Robie, as the resource provider and coordinator, is also a key contributor, having authored more than 63 articles (peer-reviewed) or reviews in $P J R$, beyond doubt the key influence on its editorial standards and character, and (to date) on its continued publication.

The editorial position of the journal is clearly marked by its eclectic range of coverage, as academic research, journalistic discourse and pedagogy; by its regional focus, and importantly, by its receptiveness to both the Pacific way (Sandra Kailahi's 'Pacificness'), and universal, Western liberal thought on human rights and the role of media. PJR gives attention to current global debates about journalism, as in the cases already mentioned, the reviews on Knightley's The Latest Casualty, and Fisk's Great War for Civilisation. The 'rights' approach — essentially journalists' insistence on the right to publish, as an extension of universal human rights - is applied in several instances from the Pacific, in the PJR. Take two examples from the very first editions: Journalists' objections to a government ban on reporters from the National Broadcasting Commission going to cover the fighting on Bougainville, (Vol 1(1), 1994); and Peter Cronau's article decrying self-censorship, (Vol 2(1), 1995).

The journal's concentration on military rule and blatant media censorship in Fiji, giving extensive attention to (this issue) in 16 editions, has committed it to an editorial these issues stand. The same is true of its agenda-setting in regard to crisis elsewhere: jailing of journalists in Tonga, threatened or actual media controls in Tahiti or PNG, bashing of an editor in Vanuatu by a senior government politician, threats also against the media in Solomon Islands, and reporting restrictions in Samoa. It has taken a position in the 'liberal-rights' and also 'social responsibility' tradition of what journalism should be, which has contributed to its respectability. An instance of esteem is the positive assessment from the European analysts Loffelholz and Rothenberger (2011), in their study of seven peer-reviewed journals in the Journalism discipline. They placed it in a category, of exhibiting concern with ethics, values, 'normative demands' and agenda setting, all

30 PACIFIC JOURNALISM REVIEW 21(1) 2015 
of which 'seem to be theories that can easily be combined with empirical research and have a solid standing in the theory portfolio of our discipline.'

The journal gives oxygen to campaigns that decry suppression of truth; it examines self-censorship by the news as something of a professional failing; it backs the efforts of journalists who want to investigate in an independent way, and calls for their protection in conflict situations. Through the selection and content of articles PJR gives oxygen to the aspirations of indigenous people of the region, to economic development and freedom from oppression, and to journalists' aspirations to build independent media systems that accord well with local cultures and interests. It has probed media ownership and its limiting effects on independent work by journalists (see media proprietors and public trust, in Vol 18(2), 2012).

If it was taking a political stance, that might seem an ambiguous stance. It is con-

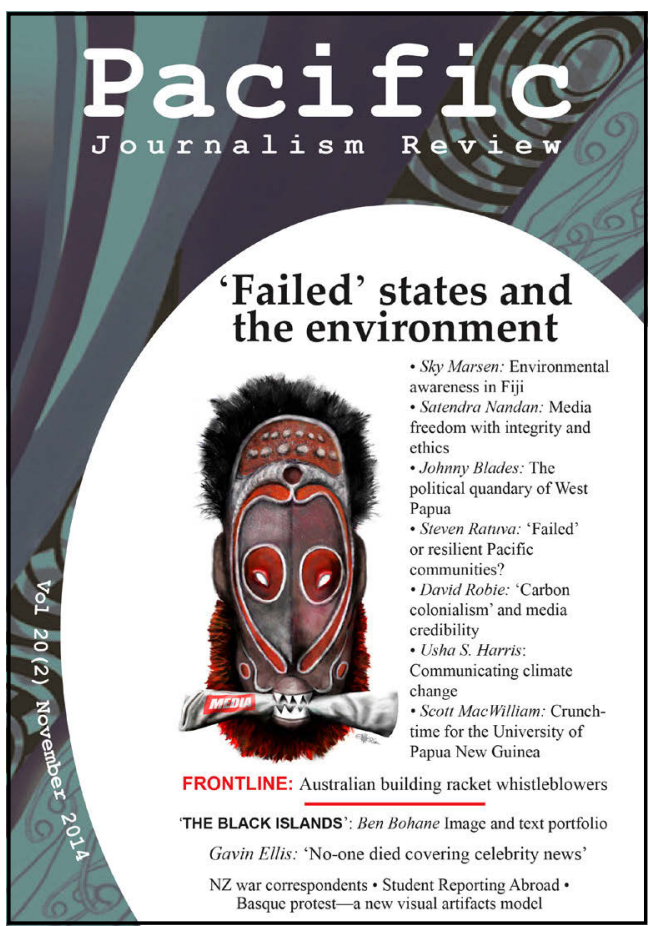

Figure 4: The latest edition of $P J R$ published last November on the 20th anniversary of the journal.

servative in the sense of wanting to preserve what is widely valued, such as freedom to find out and report; yet has no truck with domination by powerful economic interests, as in its publication of researched arguments against excesses of mining operations in Papua or New Caledonia. It might be called left-wing for its preparedness to publish a defence of the interests of the disadvantaged or disenfranchised, and respectfully observe the interests and culture of indigenous people, but does not privilege any concept of collective rights that would jeopardise private individual rights. It might be called liberal for its stress on such individual freedoms, and the wide range of its agenda, but it is not relativistic when confronted with conflicting values, e.g. those of a dictatorship against journalists wanting to openly report news across the board - there is no 'false balance'.

Pacific Journalism Review is concerned with freedom, and with truth, easily defined as the outcome of inquiries based on plain evidence. Its stance is above all journalistic; as a publishing outlet for investigative journalism, and for scholarship on media and community; as an outlet for reflective debate within the media community about its work, and as a contributor to the formation of new entrants into journalism-in their values and their aspirations to best practice. 


\section{Conclusions}

Pacific Journalism Review at age 20, with 710 articles published to the end of 2014, is able to present a track record of consistent publishing, and a clear definition that was laid out for it at the beginning. It has followed to the letter, with a good degree of success, what is now the mission statement of the PMC overall: undertaking and stimulating research into contemporary Māori, Pacific, Asia-Pacific and ethnic/diversity media and culture production; raising Aotearoa / New Zealand research capability; publishing the findings of media research; winning funding from government and industry partners; developing collaborations with other Asia-Pacific centres of research excellence in media and cultural production; developing social change and development communication editorial and publications capability, (PMC, Annual Report 2014, p. 4).

David Robie, founding it as a lecturer at the University of Papua New Guinea in 1994, took it with him on a career journey, obtaining his Chair at AUT, and ensconcing the brainchild there as an adult entity within the institutional setting of a research centre. It is a tribute to his optimism, to ensure that it would keep publishing, and keep to its task as set out at the start. That is all the more so, where, as said at the beginning of this review, things began 'going wrong' politically, with the political environment for research and publishing hostile for much of the time, over much of the geographical territory.

There is scope for more of the same publishing from PJR. In each area of interest where it has published, change continues in the region, calling for a continuation of the monitoring and research. New developments beckon, not least ongoing anxiety over climate change, options for economic development, pressure on land use, impacts of poverty, opportunities for women, life-threatening societal breakdown in villages and towns, and calls for better recognition and adaptation of 'custom' in media, as in other aspects of community life.

Through all this - as a matter of attitude — PJR shows little sense of doubt about the efficacy of its work. By 2013, after much publishing on military rule and repression of news media in Fiji, it would editorialise: 'Fiji is a tough, but not wholly insurmountable, problem.' (19(1), 2013).

\section{References}

Cap Bocage (2014). Jim Marbrook - Director, Auckland [Documentary film]. Retrieved from www.nziff.co.nz/2014/auckland/cap-bocage/

Bacon, W. (2012). An innovative direction in academic journalism. Pacific Journalism Review, $18(2), 153-165$.

Duffield, L. (2011). Submission to ARC Review, Pacific Journalism Review, Canberra, 2011, (Unpublished).

King, B. (2003). A timely alternative edition [Editorial]. Pacific Journalism Review, 9(1), 6-7.

Knight, A. (2011). Australian Journalism Professors Council, Pacific Journalism Review, submission to ERA journal review, Sydney, (Unpublished).

32 PACIFIC JOURNALISM REVIEW 21(1) 2015 
Loffelholz, M., \& Rothenberger, L. (2011). The diversity of scholarship on journalism: How journalism journals reflect theories, methods, and topics of journalism research - a content analysis (2008-09), Diversity of Journalisms. Proceedings of ECREA / CICOM Conference, Pamplona, 4-5 July 2011.

Pacific Journalism Review, Subtitle: PJR, scholarly journal, Auckland University of Technology, School of Communication Studies; University of the South Pacific, Journalism Programme, South Pacific Centre for Communication and Information in Development. Vol. 1, No. 1 November 1994, seriatim.

Pacific Journalism Review Notes (2014, September 26). Retrieved on December 19, 2014, from www.pjreview.info.

Pacific Media Centre Annual Report (2014). School of Communication Studies, February 2015.

Pacific Media Centre Media Release (2014, November 21). Conference to put lens on political journalism in Asia-Pacific.

Pacific Media Centre Media Release (2012, August 28). PJR accepted by SCOPUS in international research breakthrough.

Pacific Media Centre, Pacific Journalism Review, Audience Overview - from Google Account (2013). www.pmc.ac.nz (19 December 2014), www.pjreview.info (19 December 2014).

Pearson, M. (2013). Pacific Media Centre: report of external moderation conducted 29 April 2013-4 May 2013, Auckland University of Technology, Auckland, New Zealand.

Robie, D. (2014, February 2). Timor-Leste's Max Stahl-documenting the audiovisual and development 'war', Café Pacific. Retrieved on December 19, 2014, from http://cafepacific. blogspot.com.au/2014/02/timor-lestes-max-stahl-documenting.html.

Robie, D. (2011, March 31). Pacific Journalism Review response to Australian Journalism Professors Council inquiry for the ERA 2012 journal review, AUT, Auckland (Unpublished).

Robie, D. (2004). Mekim nius: South Pacific media, politics and education. Suva, Fiji: University of the South Pacific Book Centre.

Robie, D. (1995). Nius bilong Pasifik: Mass media in the Pacific, Port Moresby, UPNG Press.

Robie, D (1989). Blood on their banner: Nationalist struggles in the South Pacific. London, United Kingdom: Zed Books.

Wreksono, S. (2014). The Life of Pacific Journalism Review [Video documentary]. Retrieved on December 19, 2014, from www.youtube.com/watch?v=Brq_AgBS-ys.

Dr Lee Duffield is a senior lecturer at the Queensland University of Technology in Brisbane, where he is the postgraduate journalism coordinator and is engaged in postgraduate teaching, supervision and assessment. He runs an international journalism programme in both European Union countries and the Pacific. In 2014, he took a team of students to New Caledonia, Vanuatu and the Pacific Media Centre on a Pacific Affairs reporting mission. He is on the editorial board of Pacific Journalism Review and is a research associate of the PMC. Dr Duffield presented an earlier version of this article at the PJR2014 'Political journalism in the Asia-Pacific' conference at Auckland University of Technology on 27-29 November 2014.

I.duffield@qut.edu.au 